\title{
Impact of the Pacific Decadal Oscillation on relationships between temperature and the Arctic Oscillation in the USA in winter
}

\author{
Dagmar Budikova*
}

Department of Geography-Geology, Illinois State University, Normal, Illinois 61790-4400, USA

\begin{abstract}
Associated synoptic patterns of the Pacific Decadal Oscillation (PDO) significantly impact relationships between surface air temperature (SAT) and the Arctic Oscillation (AO) across the United States in winter. Using historical data (1900 to 2002) and composite analyses, this study demonstrates that without the influence of the PDO, winter SATs are most significantly altered during various phases of the AO throughout the Ohio Valley region and in the South. More specifically, extreme phases of the PDO significantly alter SAT responses to positive phases of the AO west of the Cascades, in the Ohio Valley region, and along the northeast coast of the US. SAT regimes related to negative phases of the AO are significantly modified by the different phases of the PDO across the northern Great Plains, and throughout the West. When the AO and PDO are both negative, winters are typically significantly cooler throughout the upper Midwest, the Great Plains and in the Northwest, in comparison to winters when PDO has been neutral. When the 2 indices are out of phase, winters are cooler (warmer) than during neutral PDO years west of the Cascades and warmer (cooler) east of the mountain range during the $\mathrm{AO}^{+} / \mathrm{PDO}^{-}\left(\mathrm{AO}^{-} / \mathrm{PDO}^{+}\right)$conditions. Extreme phases of the PDO modify the north-south structure of the mean sea level pressure (SLP) field over the Northern Hemisphere, these changes being consistent with the modifications observed in the SAT patterns across the study area.
\end{abstract}

KEY WORDS: Climate variability $\cdot$ Pacific Decadal Oscillation · Arctic Oscillation · Temperature $\cdot$ US

\section{INTRODUCTION}

Teleconnection patterns describe persistent atmospheric pressure anomalies that span large geographic areas and last anywhere from several weeks to several years, reflecting the variability of atmospheric circulation from interannual to decadal time scales. Teleconnection patterns manifest large-scale changes in the atmospheric wave and jet stream patterns, by influencing jet stream location and/or intensity over large areas and ultimately weather conditions (e.g. temperature, precipitation) over vast distances.

Numerous studies have addressed the relationships between climate variability and a range of atmospheric and/or oceanic oscillations or teleconnections in many regions around the world. In North America, these have predominantly included the assessment of climatic impacts associated with either the El Niño-
Southern Oscillation (ENSO) phenomenon (e.g. Mo \& Livezey 1986, Ropelewski \& Halpert 1987, 1989, Philander 1990, Halpert \& Ropelewski 1992, Budikova \& Nkemdirim 2003), the Pacific North American Pattern (PNA) (e.g. Yarnal 1985, Yarnal \& Leathers 1988, Leathers et al. 1991, Leathers \& Palecki 1992), the North Atlantic or Arctic Oscillations (NAO or AO, respectively) (e.g. Wallace \& Gutzler 1981, Rogers 1984, Thompson \& Wallace 1998, Higgins et al. 2002), or with the North Pacific or Pacific Decadal Oscillations (NPO or PDO, respectively) (e.g. Mantua et al. 1997, Gershunov \& Barnett 1998). Recently, several studies have also examined impacts related to simultaneous interactions among these teleconnection patterns, for example, that between the ENSO and PDO (e.g. Zhang et al. 1997, Cole \& Cook 1998, Gershunov \& Barnett 1998, McCabe \& Dettinger 1999, Rajagopalan \& Cook 2000, Bonsal et al. 2001, Diaz et al. 2001) and ENSO and 
NAO/AO (e.g. Rogers 1984, Mysak et al. 1996, Rodo et al. 1997, Huang et al. 1998, Higgins et al. 2002).

The AO was identified by Lorenz (1951) and Kutzbach (1970) and is now accepted as the leading mode of winter atmospheric variability over the northern hemisphere extratropics, relevant from intra-seasonal to interdecadal time scales (Thompson \& Wallace 1998). The AO represents the state of atmospheric circulation over the Arctic. It symbolizes a north-south symmetric structure characterized by barometric pressure anomalies of one sign over the Polar region and the opposite sign in the mid-latitudes, particularly over the Atlantic and to a lesser extent the Pacific Oceans (Thompson \& Wallace 1998, Thompson et al. 2000a,b, Baldwin 2001). It has also been referred to as the Northern Hemisphere annular mode (Limpasuvan \& Hartmann 1999), and Wallace (2000) argues that the well-known NAO is a regional expression of the $\mathrm{AO}$, the $\mathrm{NAO}$ being the leading mode variation over the Atlantic basin (Rogers 1984). Unlike the NAO index, which accounts for $17 \%$ of variance in winter SATs over the Northern Hemisphere, however, the AO helps explain over twice that, or $39 \%$ (Barry \& Carleton 2001). Positive (negative) phases of the AO coincide with low (high) sea level pressures (SLPs) over the Polar region and high (low) SLPs throughout the midlatitudes of the Northern Hemisphere. When the index is positive, the westerly wind flow tends to be largely zonal holding the cold Arctic air over the pole whereas during the negative phases of the AO wind flow patterns bring cold Arctic air farther south (Thompson \& Wallace 1998, Thompson et al. 2000a).

The PDO is a recurring pattern of climate variability in the tropical and extratropical Pacific Ocean (Mantua et al. 1997, Gershunov \& Barnett 1998). It represents long-term (i.e. interannual to decadal) changes in the ocean-atmosphere system over the Pacific basin (Bonsal et al. 2001) such that when sea surface temperatures (SSTs) are anomalously cool (warm) in the interior North Pacific and warm (cool) along the Pacific Coast of North America, and when SLPs are below (above) average over the North Pacific and above (below) average along western North America, a positive (negative) index or warm (cool) phase of PDO is said to prevail.

Significant modifications of the Northern Hemispheric synoptic conditions associated with the extreme phases of the AO (i.e. in the Polar regions and the mid-latitudes over the Atlantic and Pacific Oceans) and the PDO (i.e. over the tropical and north Pacific Ocean and over the North American continent) strongly influence winter surface weather patterns throughout the northern hemi- sphere. Extreme phases of the AO are known to impact winter weather patterns and ecosystems from North America (e.g. Hurrell \& van Loon 1997, Thompson \& Wallace 1998, Bonsal et al. 2001, Higgins et al. 2002, Wettstein \& Mearns 2002) through the Atlantic, and into Europe (e.g. Hurrell \& van Loon 1997, Rogers 1997, Marsh et al. 1999, Deser et al. 2000; see Table 1 in Marshall et al. 2001). High phases are typically accompanied by cold temperatures over eastern Canada and Greenland, and warm conditions and over Siberia in the subpolar belt (Wallace 2000). The opposite is true during winters dominated by low phases of the index. In the US, greatest differences in SAT patterns observed between the 2 extreme phases of the index can be observed east of the Cascades, with greatest changes taking place throughout the Great Plains and in the Midwest (Fig. 1a) (Thompson \& Wallace 1998,
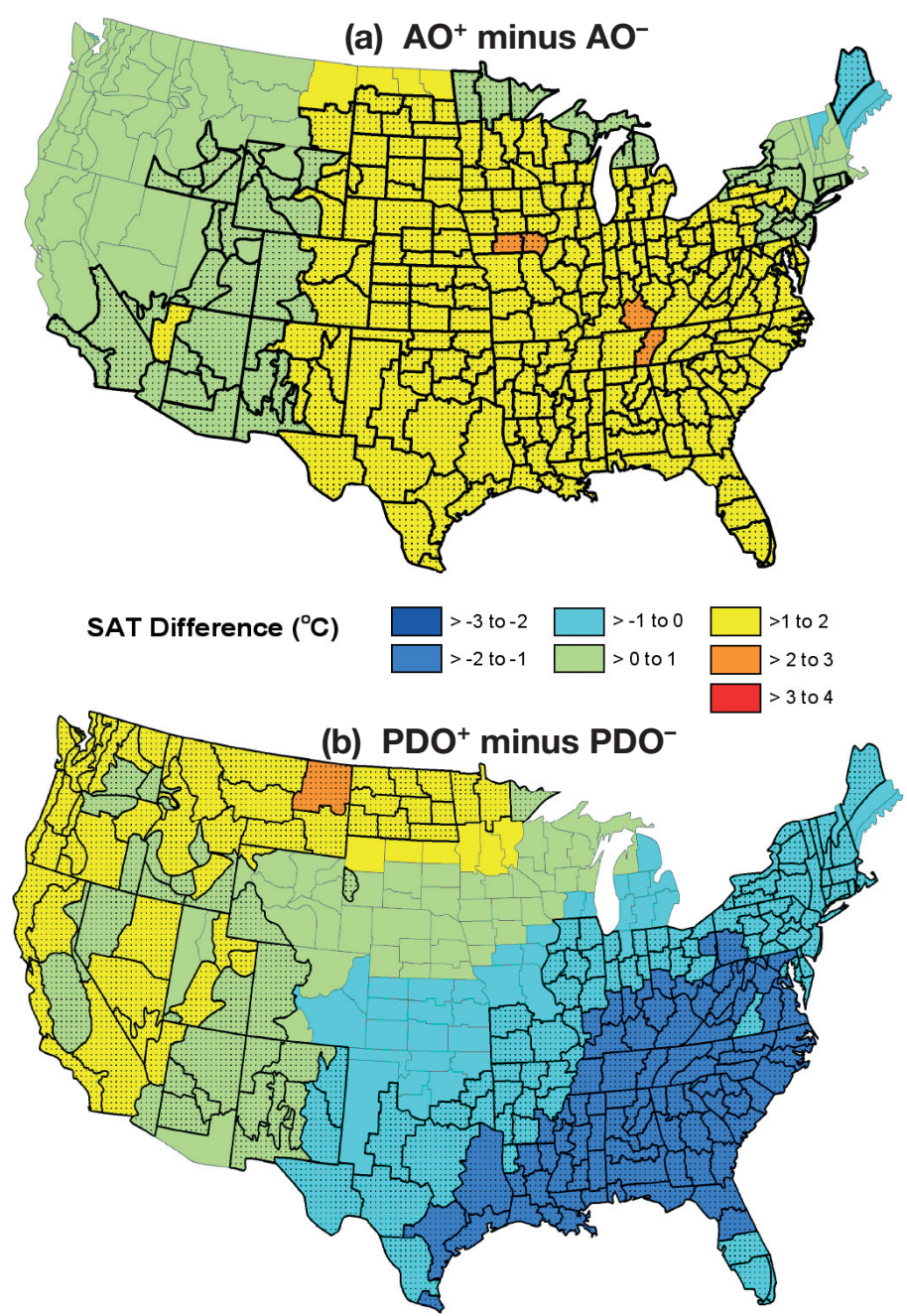

Fig. 1. Difference in winter (JFM) surface air temperature (SAT) anomalies $\left({ }^{\circ} \mathrm{C}\right)$ between the 2 extreme phases of (a) the Arctic Oscillation (AO) and (b) the Pacific Decadal Oscillation (PDO). Climate divisions with bold outlines and dots indicate areas with statistically significant differences in SAT magnitudes at the $5 \%$ level 
Higgins et al. 2002, Wettstein \& Mearns 2002). The impact of the PDO on the North American climate has also been well documented (e.g. Latif \& Barnett 1994, Trenberth \& Hurrell 1994, Mantua et al. 1997, Zhang et al. 1997, Gershunov \& Barnett 1998, Bonsal et al. 2001). Together, these studies demonstrate that North American winter climate anomalies associated with the PDO are similar to those connected with ENSO as warm phases of the PDO are correlated with El Niño-like temperature and precipitation anomalies, and cool phases of the PDO are correlated with La Niña-like climate patterns. For instance, positive (negative) phases of the PDO coincide with unseasonably cool (warm) winters throughout the East, with warmer-than-usual (cool) conditions common in northern Great Plains and throughout the West (Fig. 1b).

Separately, the synoptic conditions associated with the AO and the PDO significantly modify winter weather across several regions of the US with unseasonably warm winters common to the northern regions of the Central Plains and in many areas of the West during high phases of the AO and the PDO. In the eastern sections of the US, however, anomalously warm (cool) winters are typically observed when both indices are positive. Although the most pronounced signatures of the AO in SLP lie over the Atlantic basin, there is also a small Pacific contribution as well, just south of the Aleutian Islands (Wallace 2000), where significant modifications in the SLP and SSTA (sea surface temperature anomalies) fields are observed during extreme phases of the PDO. It is hypothesized that under different phases of the PDO, the associated state of the north Pacific basin will alter the expected SLP fields and synoptic circulation patterns associated with extreme phases of the $\mathrm{AO}$, consequently altering winter SAT conditions across the US. To that end, this study examines the changes in the large-scale circulation patterns that result from the interaction between the extreme phases of the 2 teleconnection patterns, and their impact on SAT patterns across the US in winter. Specifically, it is of interest to understand better the modifications in the relationships between large-scale circulation, SATs and the AO under various PDO regimes by examining the following: (1) the relative overall influence of the AO on winter SATs, with and without the influence of $\mathrm{PDO}_{\text {; }}$ (2) the role, if any, played by the PDO on the relationships between extreme phases of AO and SATs and (3) the synoptic patterns associated with the observed SAT conditions under various AO/PDO regimes. An improved knowledge of the interaction between various teleconnection patterns and their climatic signatures will help refine our understanding of existing climatic variation patterns and trends that together will aid in refining climate and related forecasting tools.

\section{DATA AND METHODS}

The data used in this study came from several sources. Variables include mean monthly SAT records across the US, SLP data for the Northern Hemisphere, and monthly time series of the AO and the PDO indices. Time series for mean monthly SATs spanning from 1900 through 2002 for 344 US climate divisions were obtained from the National Climatic Data Center (Asheville, NC). Guttman \& Quayle (1996) describe in detail the construction of the climate divisions, the computation of data values for each month and climate division on record, the data treatment procedures, and discuss the strengths and weaknesses of the dataset. Prior to analysis, mean winter anomalies that include the months of January, February, and March were computed based on the entire time period of record. To help account for the observed patterns of AO/PDO combinations, monthly time series of SLP data were obtained from the National Center for Atmospheric Research (NCAR dataset ds010.1) (Trenberth \& Paolino 1980). These data cover the Northern Hemisphere $\left(15^{\circ} \mathrm{N}\right.$ to $90^{\circ} \mathrm{N}$ ) from 1899 to 2002 . The resolution is $5 \times 5^{\circ}$. Also used were wintertime series of the $\mathrm{AO}$, computed as the leading empirical orthogonal function (EOF) of SLP poleward of $20^{\circ} \mathrm{N}$ between January 1900 and June 2002 (Thompson \& Wallace 2000) (Fig. 2a). These data were obtained from the Colorado State University website at www.atmos.colostate.edu/ao/Data/ao_index.html. The winter time series of the PDO derived as the standardized leading principal component of monthly SST anomalies in the North Pacific Ocean poleward of $20^{\circ} \mathrm{N}$, between 1900 and 2002 (Mantua et al. 1997, Zhang et al. 1997) was obtained from the University of Washington at http://tao.atmos.washington.edu/pdo/ and is shown in Fig. 2b. Anomalies were calculated based on the entire period of record, 1900 to 2002.

In diagnosis, the study employed compositing analyses and statistical significance testing procedures. Differences in SAT magnitudes between various AO/PDO combinations were assessed for statistical significance using $t$-tests and Monte Carlo procedures (von Storch \& Zwiers 1999), such that the SAT series of each climate division was reshuffled at random and a $t$-value calculated. This process was repeated 1000 times to produce a random distribution of $t$-values. The original $t$-statistic was then compared to this distribution to assess its significance at the $5 \%$ level.

The winter AO and PDO index series were each divided into positive, neutral, and negative phases by separating each of the distributions into thirds. Index values in the lowest third were considered as negative phases; those in the highest third of the distribution were classified as positive phases, together resulting in 9 AO/PDO combinations (Table 1). 

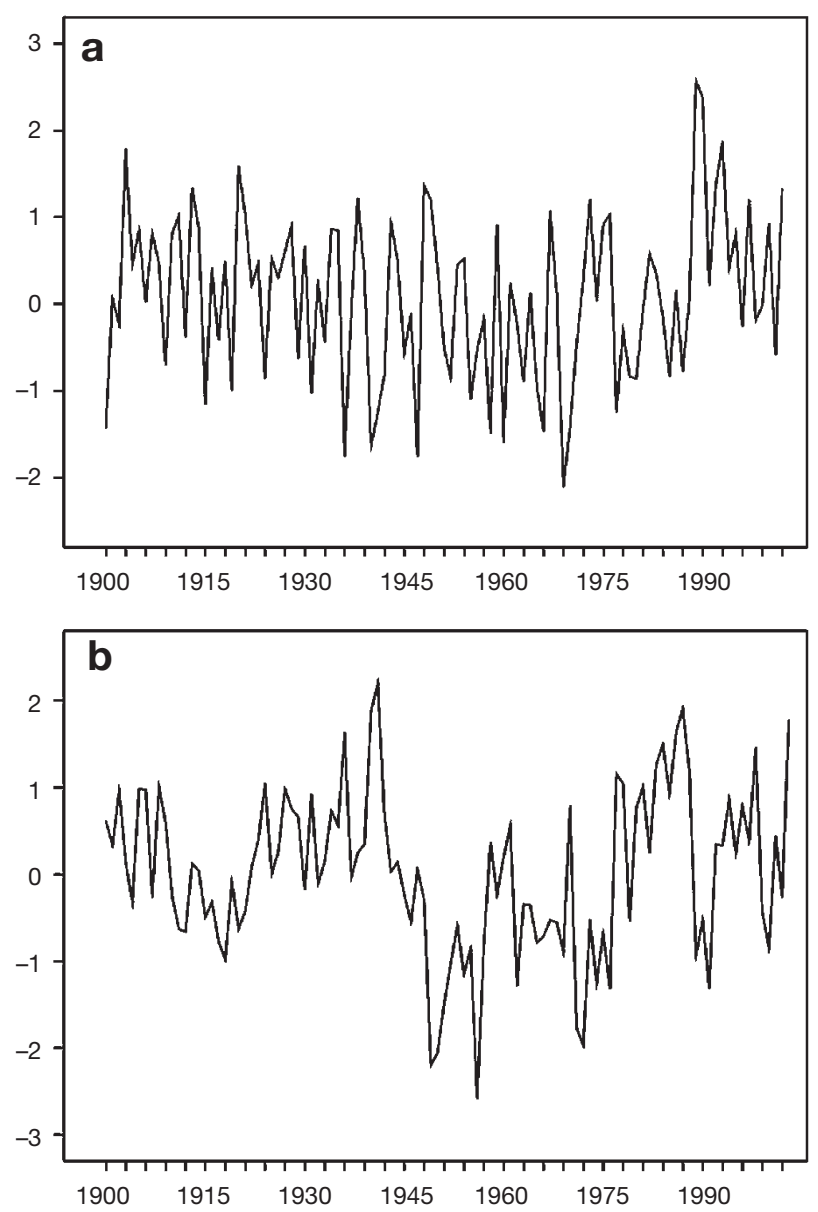

Fig. 2. Winter (JFM) time series (1900-2002) of (a) the AO and (b) the PDO indices

\section{MODIFICATION OF AO TEMPERATURE RESPONSES BY THE PDO}

Not only is there an appreciable difference between SAT modifications during winters when the $\mathrm{AO}$ has been either positive or negative, but also in those modifications observed during extreme phases of the $\mathrm{AO}$ when the PDO has been neutral (Fig. 3a). Without the influence of the PDO warm winters continue to be prevalent throughout the US when the AO is in its positive phase, with most significant increases in SATs present throughout the Southeast and in the Ohio Valley region (not shown). During the negative AO phase, however, positive SAT anomalies, in excess of $+1^{\circ} \mathrm{C}$ are prominent throughout the Great Plains, and in the northeast, with cool conditions, in excess of $-1^{\circ} \mathrm{C}$ dominating the southern regions of the country (not shown). Overall, without the presence of the PDO extreme phases of the AO most significantly modify winter SAT conditions in the southern regions of the country from southern California to Florida and throughout the Ohio Valley (Fig. 3a). Removing the influence of the PDO produces significant changes in the SAT modifications during various phases of the AO throughout many regions of the US, with greatest differences observed throughout the central Great Plains and the upper Midwest. Although these regions continue to show warmer-than-expected winter conditions during the positive phases of the $\mathrm{AO}$ when the PDO is neutral, these modifications are no longer statistically significant when compared to those observed during the other extreme phase of the AO (compare Fig. 1a to Fig. 3a).

Removing the influence of the AO also modifies the SAT response to the PDO in many regions of the US as well (compare Fig. 1b to Fig. 3b). Without the influence of the AO, extreme phases of the PDO now most significantly impact the winter SAT regimes in the Southeast and along the West Coast, with unseasonably cooler winters present in the former and warmer winters dominating the latter regions of the country during the high phases of the index (Fig. 3b). When the AO is neutral and the PDO is in its positive phase (not shown) cooler-than-expected SATs are observed throughout the eastern sections of the US, and positive temperature anomalies dominate in the West. During the negative phase of the PDO, when AO is neutral, positive SAT anomalies dominate the majority of the country, with the exception of the West Coast, the interior

Table 1. Classification of winter (JFM) years between 1900 and 2002 according to various phases of the AO and PDO

\begin{tabular}{|llll|}
\hline & Positive PDO & Negative PDO & \multicolumn{1}{c|}{ Neutral PDO } \\
\hline Positive AO & $1905,1927,1928,1934,1935$ & $\begin{array}{l}1911,1920,1949,1954,1967, \\
1973,1975,1976,1989,1990,\end{array}$ & $\begin{array}{l}1903,1907,1910,1913,1914, \\
1921,1925,1930,1938,1943, \\
1944,1948,1959,1982,1992, \\
1993,1995,1997,2002\end{array}$ \\
& & 2000 & $1919,1933,1945,1947,1958$, \\
Negative AO & $1900,1909,1924,1929,1931$, & $\begin{array}{l}1912,1915,1917,1951,1952, \\
1955,1956,1965,1966,1969,\end{array}$ & 1960,1963 \\
& $1936,1940,1941,1942,1970$, & 1971,1979 & $1901,1904,1916,1922,1926$, \\
Neutral AO & $1977,1980,1985,1987,2001$ & $1918,1946,1950,1953,1957$, & $1932,1937,1939,1964$ \\
& $1902,1908,1906,1923,1961$, & $1962,1968,1972,1974,1991$, & \\
\hline
\end{tabular}



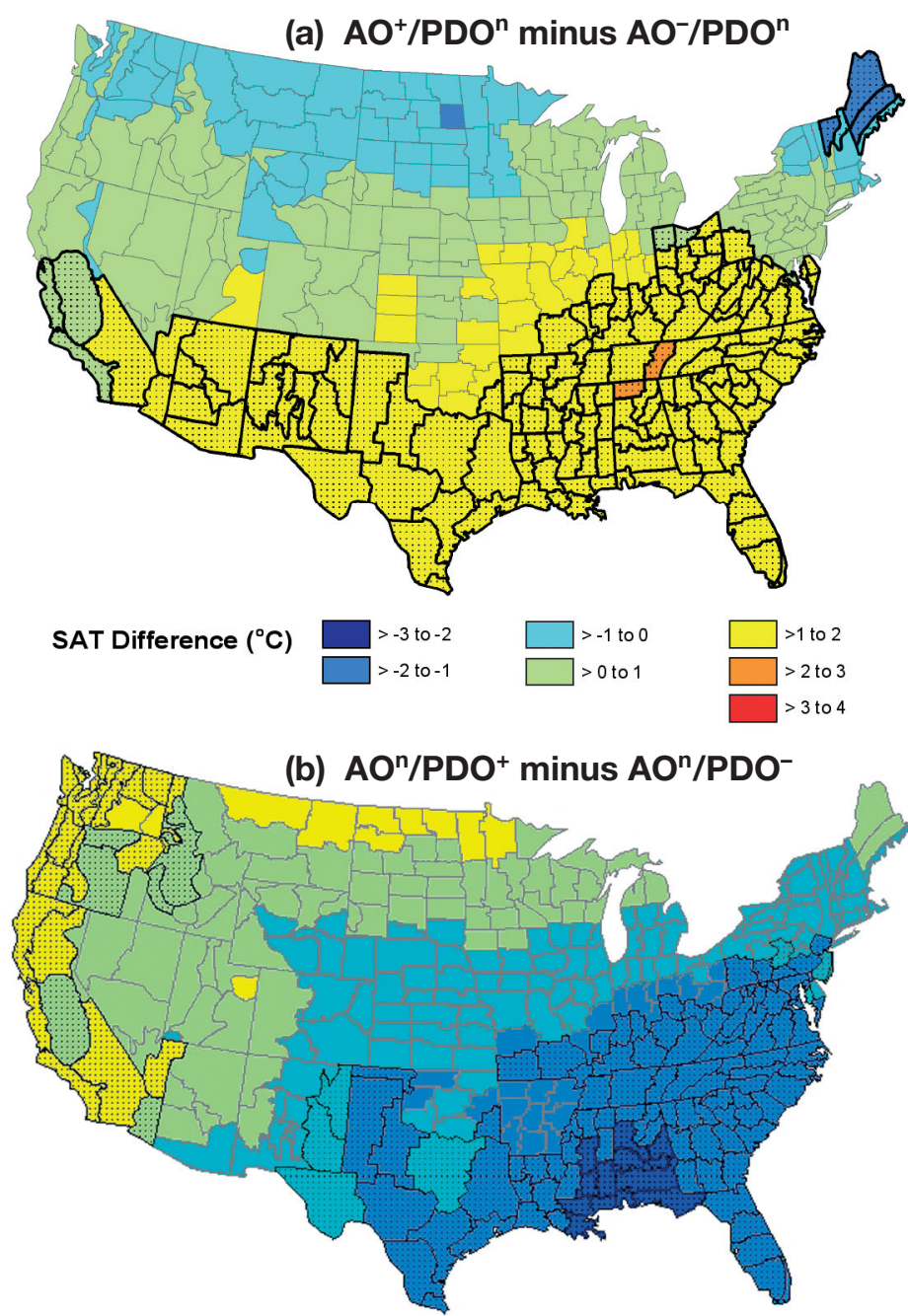

Fig. 3. Difference in winter (JFM) SAT anomalies $\left({ }^{\circ} \mathrm{C}\right)$ between the 2 extreme phases of (a) the AO under neutral PDO $\left(\mathrm{PDO}^{\mathrm{n}}\right)$ conditions; (b) the PDO under neutral $\mathrm{AO}\left(\mathrm{AO}^{\mathrm{n}}\right)$ conditions. Climate divisions with bold outlines and dots indicate areas with statistically significant differences in SAT magnitudes at the $5 \%$ level

North and the extreme Northeast, where cooler-thanexpected anomalies are typically present (not shown).

Extreme phases of the PDO significantly impact the relationships between the $\mathrm{AO}$ and winter SATs across US (Figs. 4 \& 5). When both the PDO and the AO are positive (not shown), warmer-than-expected SATs typically dominate the country, with greatest positive anomalies being present throughout Great Plains and in the West. At this time, cool conditions are prominent in the Northeast. When comparing these patterns to those observed during neutral PDO conditions (Fig. 4a), the positive anomalies observed during the $\mathrm{AO}^{+} / \mathrm{PDO}^{+}$regime are significantly higher by between 1.5 and $2.5^{\circ} \mathrm{C}$ throughout the Great Plains and in the interior West, whereas in the East cooler conditions that range between -1 and $-2^{\circ} \mathrm{C}$ dominate the area at this time. During winters when PDO has been negative, $\mathrm{AO}^{+}$related $\mathrm{SAT}$ patterns show cooler conditions west of the Cascades and positive anomalies in the East (not shown). At these times, SATs are also significantly cooler, up to $-2^{\circ} \mathrm{C}$ in comparison to winters when PDO is in its neutral phase, along the West Coast (Fig. 4b). Together, these results demonstrate and Fig. 4c confirms that extreme phases of the PDO significantly impact the $\mathrm{AO}^{+}$ related SAT responses in several areas of US, especially in the West, throughout the Ohio Valley region, and along the East Coast.

Ocean-atmosphere conditions prevalent throughout the northern Pacific also significantly influence US SAT patterns under negative AO regimes (Fig. $5 \mathrm{a}-\mathrm{C}$ ). During positive phases of the PDO, large portions of the country typically experience cool winters, with greatest departures in excess of $-1^{\circ} \mathrm{C}$ being present throughout the Southeast (not shown). During $\mathrm{AO}^{-} / \mathrm{PDO}^{-}$winters, even cooler conditions have been recorded across the country, with greatest negative anomalies up to $-3^{\circ} \mathrm{C}$ being measured throughout the northern Great Plains (not shown). When comparing these modifications to neutral PDO conditions, $\mathrm{AO}^{-}$winters have been significantly warmer along the southern coast of California and cooler in the extreme Northeast during the positive phase of the PDO, in comparison to winters with neutral PDO conditions (Fig. 5a). When examining SAT differences between neutral and negative phases of the PDO, significant SAT changes are observed throughout the northern Great Plains and in the Northwest where temperatures drop to in excess of $-3^{\circ} \mathrm{C}$ in the former region (Fig. 5b). Most significant influences of the extreme phases of the PDO on $\mathrm{AO}^{-}$related SAT regimes can be observed throughout the Great Plains and in many regions of the West, with the greatest anomalies in excess of $+3^{\circ} \mathrm{C}$ being observed throughout the northern Great Plains during the high index phases of the PDO (Fig. 5c).

\section{ATMOSPHERIC CIRCULATION MODIFICATIONS}

To explore the physical processes behind the observed SAT responses, composites of Northern Hemispheric SLPs and their anomalies associated with various $\mathrm{AO} / \mathrm{PDO}$ regimes were constructed.

\subsection{Influence of the PDO on SLP fields during the negative $\mathrm{AO}$ phase}

When the influence of the PDO is removed, $\mathrm{AO}^{-}$ related SLP anomaly patterns show the presence of positive pressure anomalies over the Polar region, cou- 

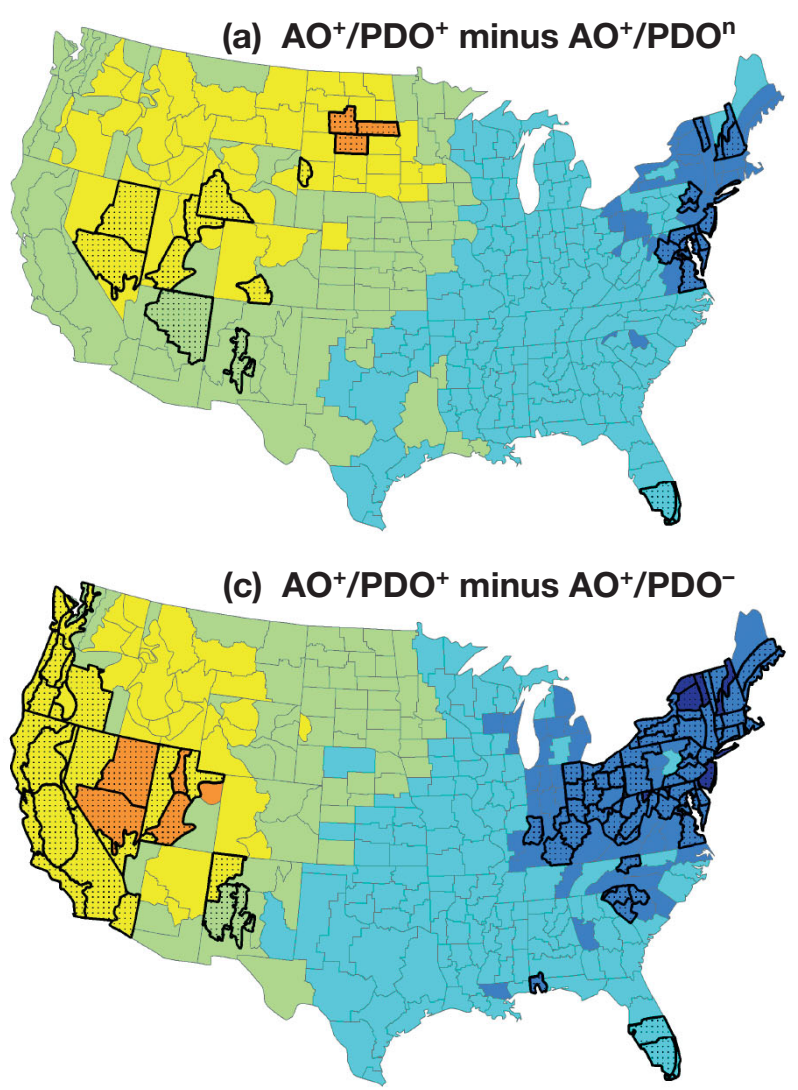

(a) $\mathrm{AO}^{-} / \mathrm{PDO}^{+}$minus $\mathrm{AO}^{-} / \mathrm{PDO}^{n}$

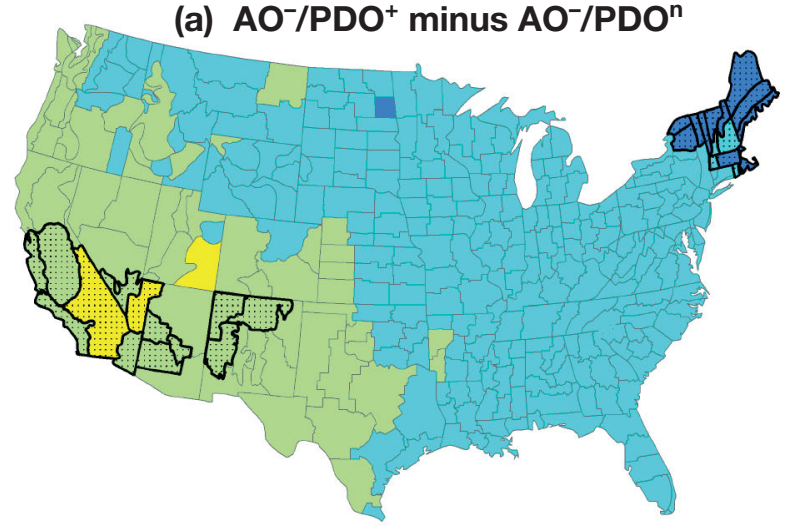

(c) $\mathrm{AO}^{-} / \mathrm{PDO}^{+}$minus $\mathrm{AO}^{-} / \mathrm{PDO}^{-}$

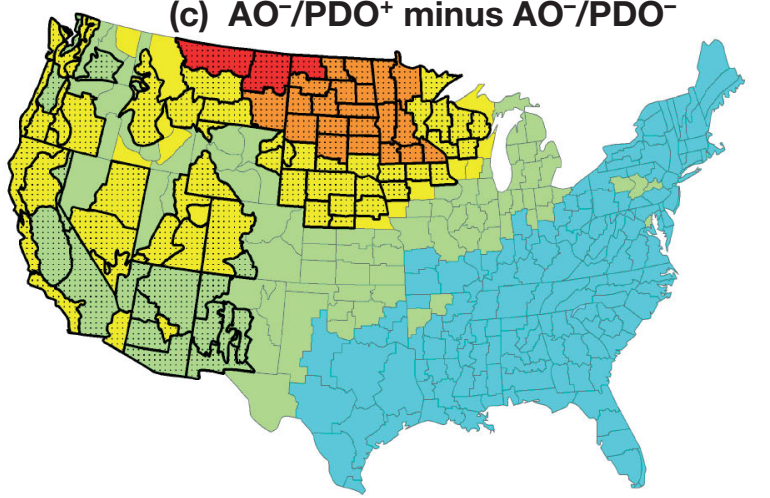

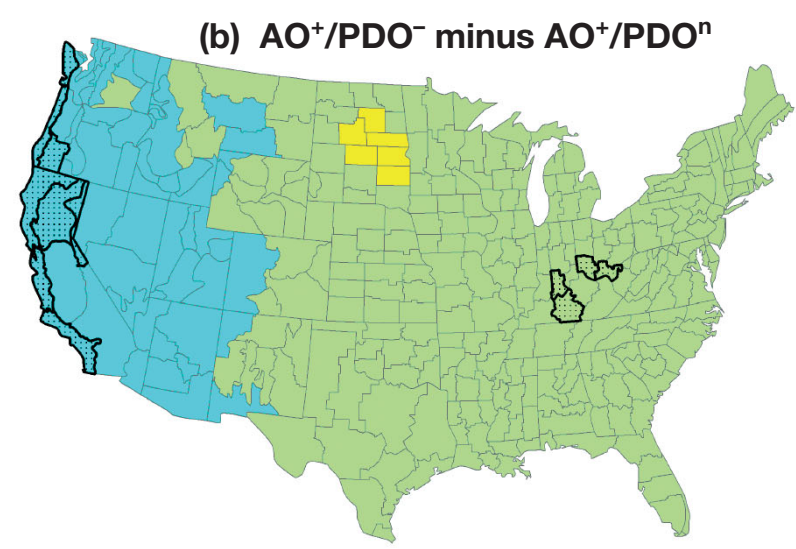

SAT Difference $\left({ }^{\circ} \mathrm{C}\right)$

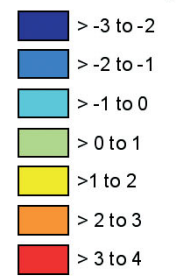

Fig. 4. Difference in winter (JFM) SAT anomalies $\left({ }^{\circ} \mathrm{C}\right)$ showing the impact of extreme phases of the PDO on SAT relationships with positive phases of AO across the US in winter. Shown are the following: (a) $\mathrm{AO}^{+} / \mathrm{PDO}^{+}$minus $\mathrm{AO}^{+} / \mathrm{PDO}^{n}$; (b) $\mathrm{AO}^{+} / \mathrm{PDO}^{-}$minus $\mathrm{AO}^{+} / \mathrm{PDO}^{n}$; and (c) $\mathrm{AO}^{+} / \mathrm{PDO}^{+}$minus $\mathrm{AO}^{+} / \mathrm{PDO}^{-}$. Climate divisions with bold outlines and dots indicate areas with statistically significant differences in SAT magnitudes at the $5 \%$ level

\section{(b) $\mathrm{AO}^{-} / \mathrm{PDO}^{-}$minus $\mathrm{AO}^{-} / \mathrm{PDO}^{\mathrm{n}}$}

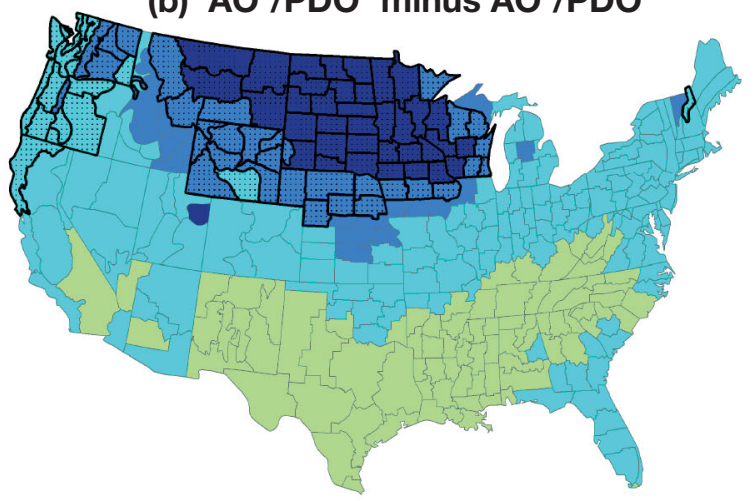

SAT Difference $\left({ }^{\circ} \mathrm{C}\right)$

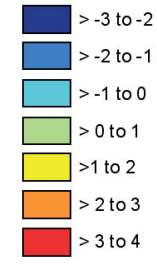

Fig. 5. Difference in winter (JFM) SAT anomalies $\left({ }^{\circ} \mathrm{C}\right)$ showing the impact of extreme phases of the PDO on SAT relationships with negative phases of AO across US in winter. Shown are the following: (a) $\mathrm{AO}^{-} / \mathrm{PDO}^{+}$minus $\mathrm{AO}^{-} / \mathrm{PDO}^{n_{i}}$ (b) $\mathrm{AO}^{-} / \mathrm{PDO}^{-}$minus $\mathrm{AO}^{-} / \mathrm{PDO}^{n}$; and (c) $\mathrm{AO}^{-} / \mathrm{PDO}^{+}$minus $\mathrm{AO}^{-} / \mathrm{PDO}^{-}$. Climate divisions with bold outlines and dots indicate areas with statistically significant differences in SAT magnitudes at the $5 \%$ level 
pled with a belt of negative anomalies throughout the mid-latitudes of the Northern Hemisphere, greatest departures present over Greenland (rise in SLPs) and over the Atlantic basin (drop in SLPs) (Fig. 6a). Such conditions indicate a well-developed Arctic high pressure center over the Pole, coupled with a weakened Aleutian low over the central North Pacific and Bermuda high over the Atlantic basin (Fig. 6b). In general, this synoptic circulation pattern is preserved when the PDO turns positive (Fig. 6c). The only difference includes the weakening of the high pressure cell over the Pacific off the west coast of the US during the positive phase of the PDO, with greatest SLP anomalies being observed off the California Coast that coincide with the observed unseasonably warm winters across regions of southern California and throughout western Arizona. During negative phases of the PDO, SLPs rise over the Western Hemisphere, with the greatest changes in the synoptic circulation patterns being observed over the area extending from the central North Pacific, through central Canada and into Northeastern sections of the US (Fig. 6d). Such conditions signify a weakened Aleutian low coupled with a southward extent of the Polar high into the US, possibly resulting in an increased flow of cold northerly air into the area, making such winters extremely cool throughout the country especially throughout the
Great Plains region. The impact of the extreme phases of the PDO on synoptic conditions observed during the negative phases of the AO is most pronounced over the North Pacific and over northeastern Canada, as SLPs drop over these areas during the positive phase of the PDO (Fig. 6e). As a result, the presence of a stronger low pressure center over the northern Pacific during the positive phase of the PDO coupled with a weakened influence from the Arctic high pressure, may encourages the influx of Pacific air from the West and Southwest onto the North American continent, resulting in warmer-than-expected winter conditions over these areas during these periods.

\subsection{Influence of the PDO on SLP fields during the positive AO phase}

Various phases of the PDO also alter the $\mathrm{AO}^{+}$related atmospheric circulation patterns over the Northern Hemisphere. When the PDO is in its neutral phase and the $\mathrm{AO}$ is positive (Fig. 7a), negative pressure anomalies dominate over the Polar area and high pressure anomalies are present throughout the mid-latitudes of the Northern Hemisphere. These conditions are indicative of a weaker Aleutian low over the central Pacific, Arctic high over north central Canada, as well (a) $\mathrm{AO}^{-} / \mathrm{PDO}^{\mathrm{n}}$ SLPA

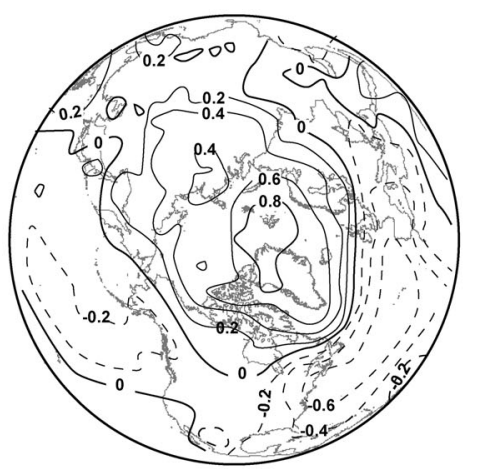

(d) $\mathrm{AO}^{-} / \mathrm{PDO}^{-}$minus $\mathrm{AO}^{-} / \mathrm{PDO}^{n}$

Fig. 6. Difference in winter (JFM) sea level pressure (SLP) (mb) and SLP anomaly (SLPA) (z) fields over the Northern Hemisphere during negative phases of the $\mathrm{AO}$ under various PDO regimes. (a) SLPA under neutral PDO conditions, (b) SLP under neutral $\mathrm{PDO}$ conditions, (c) $\mathrm{AO}^{-} / \mathrm{PDO}^{+}$minus $\mathrm{AO}^{-} / \mathrm{PDO}^{\mathrm{n}}$, (d) $\mathrm{AO}^{-} / \mathrm{PDO}^{-}$minus $\mathrm{AO}^{-} / \mathrm{PDO}^{\mathrm{n}}$, (e) $\mathrm{AO}^{-} / \mathrm{PDO}^{+}$minus $\mathrm{AO}^{-} / \mathrm{PDO}^{-}$ (b) $\mathrm{AO}^{-} / \mathrm{PDO}^{\mathrm{n}} \mathrm{SLP}$
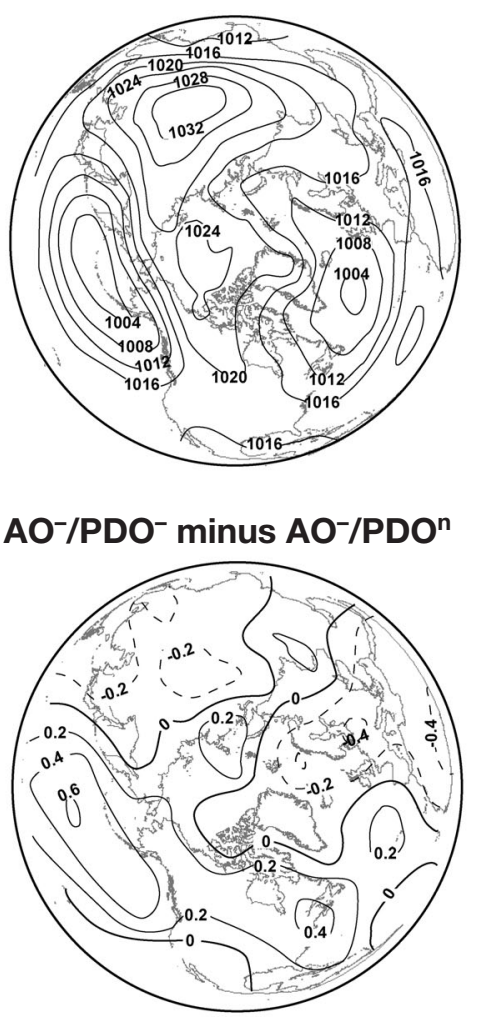

(c) $\mathrm{AO}^{-} / \mathrm{PDO}^{+}$minus $\mathrm{AO}^{-} / \mathrm{PDO}^{n}$

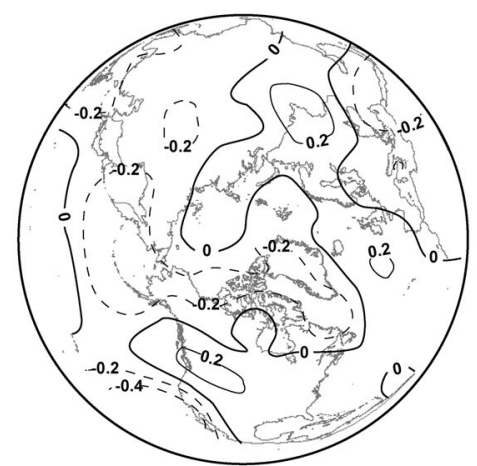

(e) $\mathrm{AO}^{-} / \mathrm{PDO}^{+}$minus $\mathrm{AO}^{-} / \mathrm{PDO}^{-}$

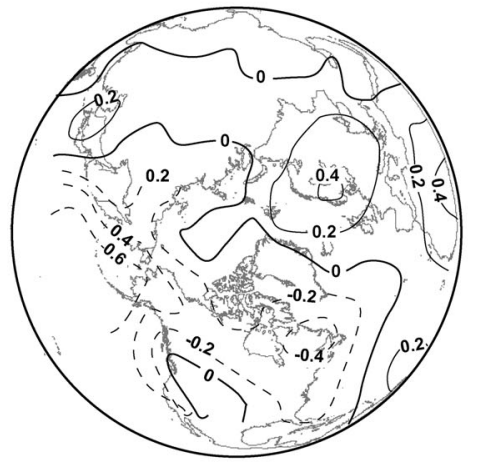


(a) $\mathrm{AO}^{+} / \mathrm{PDO}^{\text {n }}$ SLPA

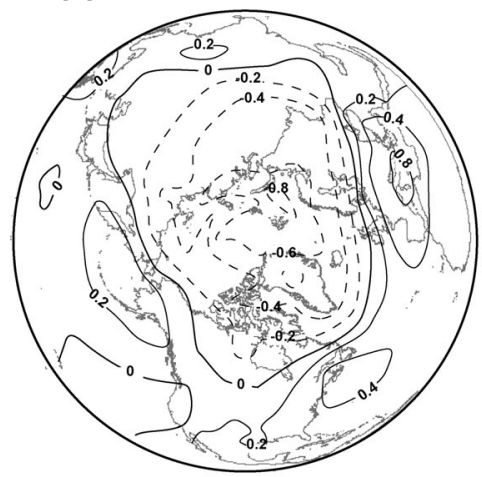

(d) $\mathrm{AO}^{+} / \mathrm{PDO}^{-}$minus $\mathrm{AO}^{+} / \mathrm{PDO}^{n}$

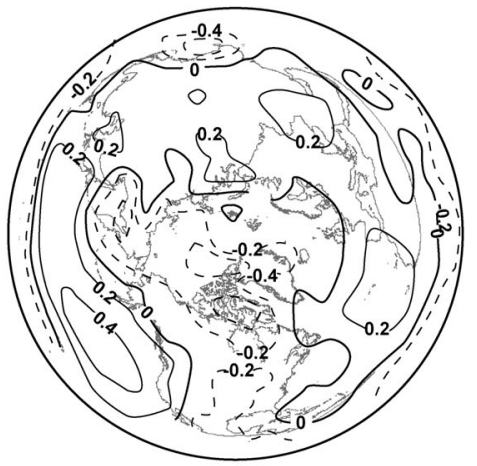

(b) $\mathrm{AO}^{+} / \mathrm{PDO}^{\mathrm{n}} \mathrm{SLP}$

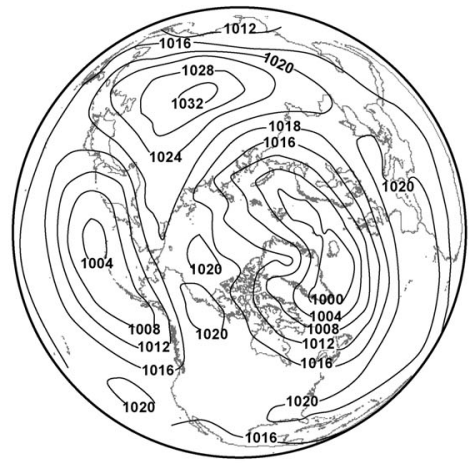

(e) $\mathrm{AO}^{+} / \mathrm{PDO}^{+}$minus $\mathrm{AO}^{+} / \mathrm{PDO}^{-}$

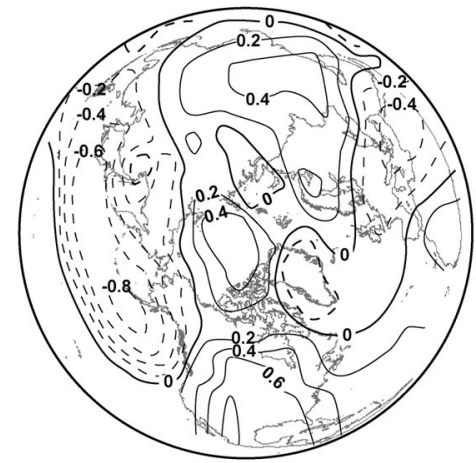

(c) $\mathrm{AO}^{+} / \mathrm{PDO}^{+}$minus $\mathrm{AO}^{+} / \mathrm{PDO}^{\mathrm{n}}$

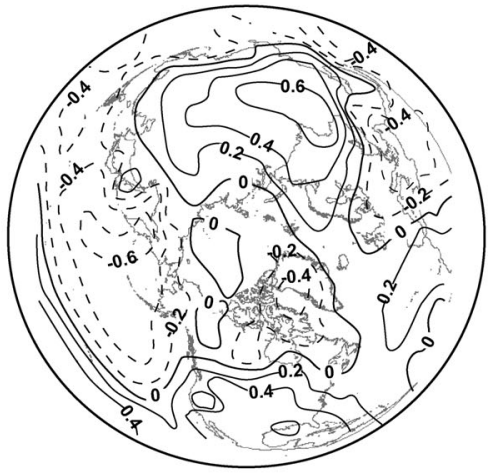

Fig. 7. Difference in winter (JFM) SLP (mb) and SLPA (z) fields over the Northern Hemisphere during positive phases of the $\mathrm{AO}$ under various PDO regimes. (a) SLPA under neutral PDO conditions, (b) SLP under neutral PDO conditions, (c) $\mathrm{AO}^{+} / \mathrm{PDO}^{+}$ minus $\mathrm{AO}^{+} / \mathrm{PDO}^{\mathrm{n}}$, (d) $\mathrm{AO}^{+} / \mathrm{PDO}^{-}$minus $\mathrm{AO}^{+} / \mathrm{PDO}^{\mathrm{n}}$, (e) $\mathrm{AO}^{+} / \mathrm{PDO}^{+}$minus $\mathrm{AO}^{+} / \mathrm{PDO}^{-}$

as a deeper low over Greenland and Iceland and a well-developed high pressure area over western Atlantic, eastern sections of Canada, and the US (Fig. 7b). The low pressure centers situated over the north-central and eastern North Pacific as well as over Greenland and north-eastern Canada intensify once PDO switches to a positive phase. These changes are accompanied by rising pressures over the Gulf and central regions of the US (Fig. 7c). The resulting synoptic conditions coincide with a cooling throughout the eastern sections of the US and a warming in the central regions and to the west, however, with no appreciable coherent areas with significant departures from conditions observed during neutral PDO phases. When the PDO switches from its neutral to negative phase, the synoptic conditions associated with positive phases of the AO over the Northern Hemisphere are also altered. Negative phases of the PDO coincide with a general rise of SLPs over the eastern North Pacific and a drop in SLPs over the Polar region and Greenland (Fig. 7d). Such conditions signify a weakening of the general SLP structure over the North Pacific, accompanied by a strengthening of the high pressure cell typically present just west of the California coast, a further weakening of the high pressure cell present over the high latitudes of the Northern Hemisphere and a general drop in SLPs over central North America. The increased influence of the high pressure cell off the West Coast may be responsible for bringing cool northerly air onto the coastal and western regions of the US.

Together, the 2 extreme phases of the PDO modify the synoptic conditions over the western regions of the Northern Hemisphere during the positive phases of the AO in several respects (Fig. 7e). During the positive phase of the PDO, SLPs drop over the eastern North Pacific Ocean, south of Alaska. At the same time, SLPs rise over the central sections of the North American continent, with greatest departures in the Polar areas and throughout the southern and central regions of the US (Fig. 7e). The synoptic conditions associated with the positive phase of the PDO may enhance the influx of southwesterly Pacific air onto the West Coast, bringing unseasonably warm air into those areas. In the east, the intensification of the low pressure area over Greenland and Labrador, coupled with the presence of the high pressures over the North American continent, may promote a northerly to northwesterly airflow to over the eastern sections of the US, bringing unseasonably cold air into those areas when PDO is in its positive phase (Fig. 7e).

\section{SUMMARY AND CONCLUSIONS}

Separately, both the PDO and the AO significantly modify winter SAT patterns across the US. Without the 
influence of the AO, however, extreme phases of the PDO most significantly modify SAT conditions along the West Coast and throughout the Southeast, whereas without the influence of the PDO, extreme phases of the AO most influence the southern sections of the country, from California through Florida, and in the Ohio Valley region. This study demonstrates that the Northern Hemispheric circulation patterns associated with the various phases of the PDO modify the AOrelated SAT responses in many regions of the US. Extreme phases of the PDO most significantly alter $\mathrm{AO}^{-}$related US SAT regimes across Great Plains and in the West, whereas maximum influences on $\mathrm{AO}^{+}$ related SAT regimes are observed west of the Cascades, in the Ohio Valley region, and along the northern East Coast. Furthermore, greatest SAT changes are common throughout the Great Plains and in the West when AO and PDO are negative, with anomalously cool winters being observed in those areas. When the 2 indices are out of phase, winters are cool in the West, with significant departures observed along the West Coast during $\mathrm{AO}^{+} / \mathrm{PDO}^{-}$conditions, in comparison to PDO neutral years.

The state of the North Pacific as described by the PDO alters the synoptic conditions over the Northern Hemisphere typically observed during extreme phases of the AO. Greatest modifications are observed in the structure of the north-south SLPs over the north Atlantic and Pacific basins as expressed by changes observed in the strength, geographic extent, and general position of the Aleutian and Icelandic lows, and the Azores and Arctic high pressure centers. The SAT signatures observed during various AO/PDO regimes were found to be consistent with the circulation anomalies present over the Northern Hemisphere at similar times.

This study made an attempt to isolate the separate impact of the AO and PDO on US winter SATs. It is, however, important to note that regardless, the 2 are not unique climate forcing mechanisms independent from the influence of other teleconnections such as ENSO and the PNA pattern or long-term climate trends. For instance, Gershunov \& Barnett (1998) point to the connection between the PDO and ENSO, and others suggest that both the AO (e.g. Thompson et al. 2000b) and the PDO (Livezey \& Smith 1999) are important components of the global warming signal. As a result the impacts on weather and associated synoptic patterns will be influenced by other teleconnection patterns as well.

The AO is an important mode of winter climate variability in many regions of the US and some studies point to its potential as source for seasonal climate prediction (Higgins et al. 2002). This study helps us understand how the complex spatial patterns of the SAT signatures associated with the AO across the US are modified by other atmospheric and oceanic forcings acting in concert, here described by the PDO, by demonstrating that the slowly varying state of the Northern Pacific has been important in modifying relationships between the $\mathrm{AO}$ and winter SAT regimes across many parts of the country during the last century.

\section{LITERATURE CITED}

Baldwin MP (2001) Annular modes in global daily surface pressure. Geophys Res Lett 30:4115-4118

Barry RG, Carleton AM (2001) Synoptic and dynamic climatology. Routledge, London

Bonsal BR, Shabbar MA, Higuchi K (2001) Impacts of low frequency variability modes in Canadian winter temperatures. Int J Climatol 21:95-108

Budikova D, Nkemdirim LC (2003) Intra-El Niño variability of surface air temperature signals across western Canada. Phys Geog 24:1-25

Cole JE, Cook ER (1998) The changing relationship between ENSO variability and moisture balance in the continently United States. Geophys Res Lett 25:4529-4532

Deser C, Walsh JE, Timlin MS (2000) Arctic sea ice variability in the context of recent wintertime atmospheric circulation trends. J Clim 13:617-633

Diaz HF, Hoerling MP, Eischeid JK (2001) ENSO variability, teleconnections and climate change. Int J Climatol 21: 1845-1862

Gershunov A, Barnett TP (1998) Interdecadal modulation of ENSO teleconnections. Bull Am Meteorol Soc 79: $2715-2726$

Guttman NB, Quayle RG (1996) A historical perspective of US climate divisions. Bull Am Meteorol Soc 77:293-303

Halpert MS, Ropelewski CF (1992) Surface temperature patterns associated with the Southern Oscillation. J Clim 5: 577-93

Higgins RW, Leetmaa A, Kousky VE (2002) Relationships between climate variability and winter temperature extremes in the United States. J Clim 15:1555-1572

Huang JP, Higuchi K, Shabbar A (1998) The relationship between the North Atlantic Oscillation and the El NiñoSouthern Oscillation. Geophys Res Lett 25:2707-2710

Hurrell JW, van Loon H (1997) Decadal variations in climate associated with the North Atlantic Oscillation. Clim Change 36:301-326

Kutzbach JE (1970) Large-scale features of monthly mean Northern Hemisphere anomaly maps of sea-level pressure. Mon Weather Rev 98:708-716

Latif M, Barnett TP (1994) Causes of decadal climate variability over the North Pacific and North America. Science 266:634-637

Leathers DJ, Palecki MA (1992) The Pacific/North American teleconnection pattern and United States climate. Part II: Temporal characteristics and index specification. J Clim 5: 707-716

Leathers DJ, Yarnal B, Palecki MA (1991) The Pacific/North American teleconnection pattern and United States climate. Part I: Regional temperature and precipitation associations. J Clim 4:517-528

Limpasuvan V, Hartmann DL (1999) Eddies and the annular Modes of climate variability. Geophys Res Lett 28: 3133-3136

Livezey RE, Smith TM (1999) Covariability of aspects of North 
American climate with global sea surface temperatures on interannual to interdecadal time scales. J Clim 12:289-302

Lorenz EN (1951) Seasonal and irregular variations of the northern hemisphere sea-level pressure profile. J Meteorol 8:52-9

Mantua NJ, Hare SR, Zhang Y, Wallace JM, Francis RC (1997) A Pacific interdecadal climate oscillation with impacts on salmon production. Bull Am Meteorol Soc 78:1069-1079

Marsh R, Petrie B, Weidman CR, Dickson RR, Loder JW, Hannah CG, Frank K, Drinkwater K (1999) The 1882 tilefish kill-a cold event in shelf waters off the north-eastern United States? Fish Oceanogr 8:39-49

Marshall J, Kushnir Y, Battisti D, Chang P and 6 others (2001) North Atlantic climate variability: Phenomena, impacts and mechanisms. Int J Climatol 21:1863-1898

McCabe GJ, Dettinger MD (1999) Decadal variations in the strength of ENSO teleconnections with precipitation in the western United States. Int J Climatol 19:1399-1410

Mo K, Livezey RE (1986) Tropical-extratropical geopotential height teleconnections during the northern hemisphere winter. Mon Weather Rev 114:2488-515

Mysak LA, Ingram RG, Wang J, van der Baaren A (1996) The anomalous sea-ice extent in Hudson Bay, Baffin Bay and the Labrador Sea during 3 simultaneous NAO and ENSO episodes. Atmos-Ocean 34:313-343

Philander SGH (1990) El Niño, La Niña, and the Southern Oscillation. Academic Press, San Diego, CA

Rajagopalan B, Cook E (2000) Spatiotemporal variability of ENSO and SST teleconnections to summer drought over the United States during twentieth century. J Clim 13: 4244-4255

Rodo X, Baert E, Comin FA (1997) Variations in seasonal rainfall in southern Europe during present century: relationships with the North Atlantic Oscillation and the El Niño-Southern Oscillation. Clim Dyn 13:275-284

Rogers JC (1984) The association between the North-Atlantic Oscillation and the Southern Oscillation in the Northern Hemisphere. Mon Weather Rev 112:1999-2015

Rogers JC (1997) North Atlantic storm track variability and its association to the north Atlantic oscillation and climate

Editorial responsibility: Daniel Leathers, Newark, Delaware, USA variability of northern Europe. J Clim 10:1635-1647

Ropelewski CF, Halpert MS (1987) Global and regional scale precipitation patterns associated with El Nino/Southern Oscillation. Mon Weather Rev 114:2352-62

Ropelewski CF, Halpert MS (1989) Precipitation patterns associated with the high index phase of the Southern Oscillation. J Clim 2:268-84

Thompson DWJ, Wallace JM (1998) The Arctic Oscillation in the wintertime geopotential height and temperature fields. Geophys Res Lett 25:1297-1300

Thompson DWJ, Wallace JM, Hegerl GC (2000a) Annular modes in the extratropical circulation. Part I: Month-tomonth variability. J Clim 13:1000-1016

Thompson DWJ, Wallace JM, Hegerl GC (2000b) Annular modes in the extratropical circulation. Part II: Trends. J Clim 13:1018-1036

Trenberth KE, Hurrell JW (1994) Decadal atmosphere-ocean variations in the Pacific. Clim Dyn 9:303-319

Trenberth KE, Paolino DA (1980) The northern hemisphere sea-level pressure dataset: trends, errors and discontinuities. Mon Weather Rev 108:855-872

von Storch H, Zwiers FW (1999) Statistical analysis in climate research. Cambridge University Press, Cambridge

Wallace JM (2000) North Atlantic Oscillation/annular mode: two paradigms - one phenomenon. Q J R Meteorol Soc 126:791-812

Wallace JM, Gutzler DS (1981) Teleconnections in the geopotential height field during the northern hemisphere winter. Mon Weather Rev 109:784-812

Wettstein JJ, Mearns LO (2002) The influence of the North Atlantic-Arctic Oscillation on mean, variance and extremes of temperature in the northeastern United States and Canada. J Clim 15:3586-3600

Yarnal BM (1985) Extratropical teleconnections associated with ENSO events. Prog Phys Geogr 9:315-352

Yarnal BM, Leathers DJ (1988) Relationships between interdecadal and interannual climate variations and their effect on Pennsylvania climate. Ann Assoc Am Geogr 78:624-641

Zhang Y, Wallace JM, Battisti DS (1997) ENSO-like interdecadal variability: 1900-93. J Clim 10:1004-1020

Submitted: September 1, 2004; Accepted: June 3, 2005

Proofs received from author(s): September 8, 2005 